\title{
Consumer Attitude and Behavior of Religious Consumers Towards Offensive Advertisements
}

\section{Alina Rashid (Shaukat Khanum Memorial Cancer Hospital And Research Centre, Lahore Pakistan) Nasar Sayeed Khan (Queens University, Kingston Canada)}

Aim - The study attempts to investigate the effect of controversial advertisements on consumer attitude of religious consumers and to find out how it reflects in their purchase intention and consequently in their buying behavior. The study also aims to investigate what difference of attitude is prevailing between men and women.

Method - 200 participants ranging in age from 20 to 25 at first were randomly selected from 3 different institutes of Lahore. Religious Commitment Inventory - 10 was distributed to the 200 participants. 40 participants (20 males; 20 females) having the highest and nearly equal scores on the $\mathrm{RCl}-10$ were selected. The selected participants were shown censored advertisements first and the responses were collected on Consumer Attitude Questionnaire and Juster's 11 Point Probability Scale. After collecting the questionnaires, participants were shown uncensored versions of the same advertisements, and responses were then collected again on same scales. The pre and post testing allowed recording any disparity in Consumer Attitude and Purchase Intention of the participants that arose after watching the uncensored advertisement.
Results - The analysis of results using $t$ test and Pearson Correlation Co-efficient suggested that controversial advertisements negatively affect the consumer attitudes of religious consumers. It is suggested that females with high religiosity are more offended by controversial advertisements as compared to males with high religiosity. However, the analysis of results showed that consumer attitude is not a strong predictor of consumer behavior, as there might be other mediating and moderating variables that shape the ultimate purchase intention and consumer behavior of religious consumers.

Mean, Standard Deviation, Paired sample t-test and $p$ value of Pre and Post Consumer Attitude of Religious Consumers

\begin{tabular}{ccccc}
\hline Variables & M & SD & $t$ & $p$ \\
\hline Pre Attitude & 16.63 & 2.789 & & \\
& & & 14.113 & .000 \\
Post Attitude & 9.28 & 2.846 & & \\
\hline
\end{tabular}

Note: ${ }^{*} p<0.05$

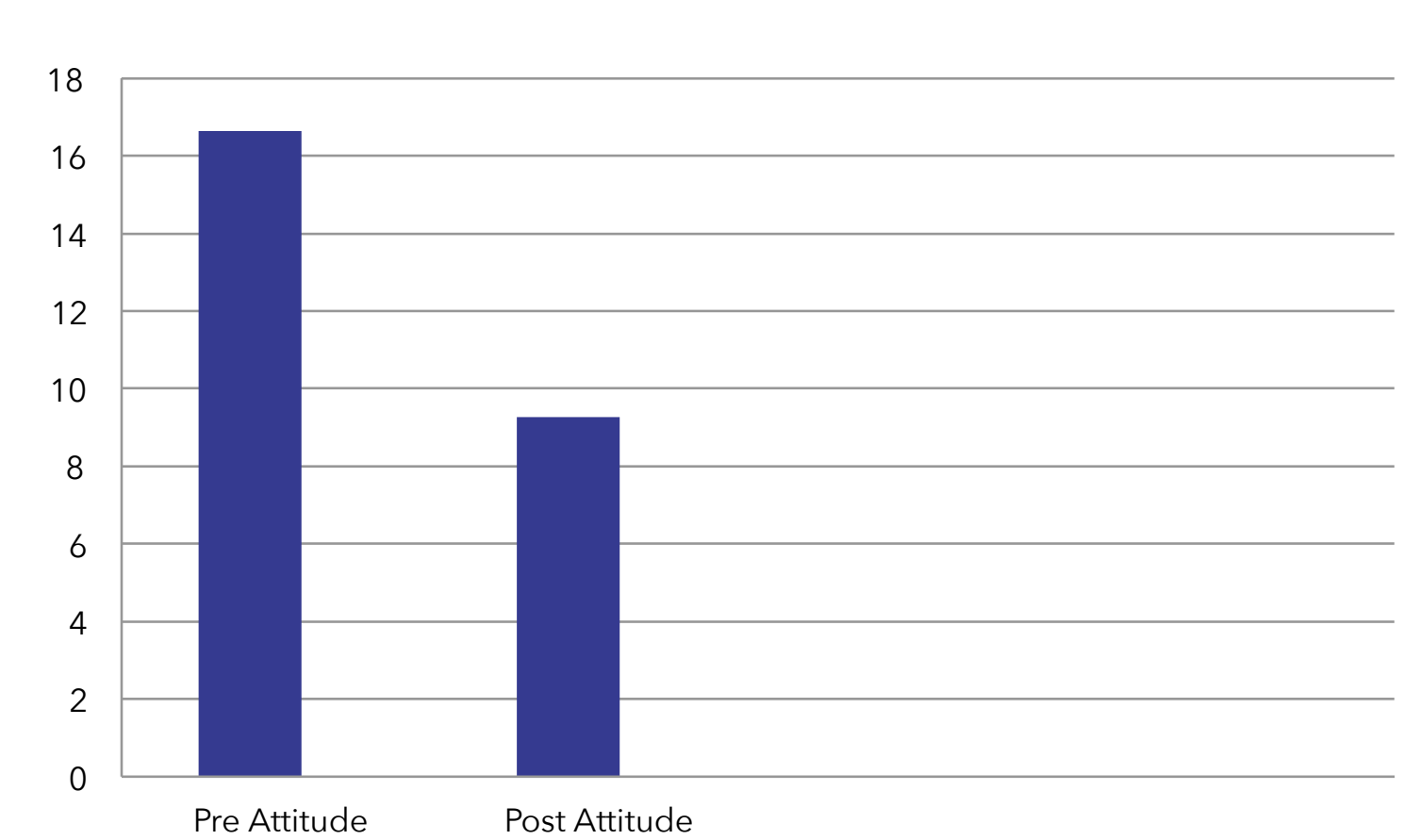

Mean of Pre and Post Consumer Attitude of Religious Consumers

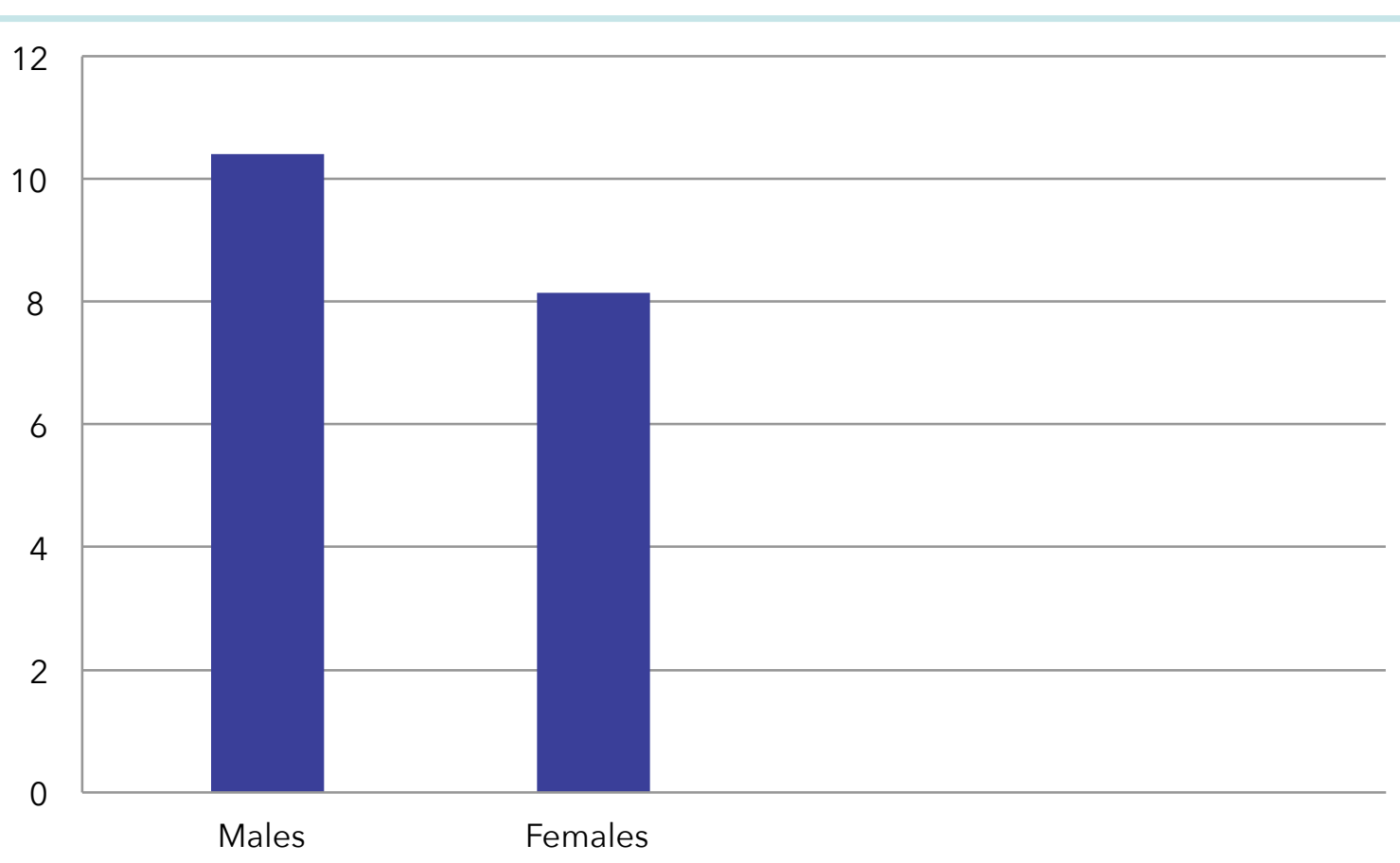

Mean of Post Consumer Attitude of Males and Females Religious Consumers 